\title{
Effects of B on the Structure and Properties of Lead-Tin Bronze Alloy and the Mechanism of Strengthening and Toughening
}

\author{
Xiaoyan Ren ${ }^{1}$, Guowei Zhang ${ }^{2, *}$, Hong Xu ${ }^{2}$, Zhaojie Wang ${ }^{2}$, Yijun Liu ${ }^{2}$, Fenger Sun ${ }^{2}$, Yuanyuan Kang ${ }^{2}$, \\ Mingjie Wang ${ }^{2}$, Weize $\mathrm{Lv}^{2}$ and Zhi Yin ${ }^{2}$ \\ 1 Department of Mechanical Engineering, Taiyuan Institute of Technology, Taiyuan 030008, China; \\ renxiaoyan03@126.com \\ 2 School of Materials Science and Engineering, North University of China, Taiyuan 030051, China; \\ xuhong@nuc.edu.cn (H.X.); wzj1997vip@163.com (Z.W.); 155366264094@163.com (Y.L.); \\ sunfengr@126.com (F.S.); kangyy469627632@163.com (Y.K.); 15513882577@163.com (M.W.); \\ lwz-1st@163.com (W.L.); yinzhi1109@126.com (Z.Y.) \\ * Correspondence: zgw@nuc.edu.cn
}

Citation: Ren, X.; Zhang, G.; Xu, H.; Wang, Z.; Liu, Y.; Sun, F.; Kang, Y.; Wang, M.; Lv, W.; Yin, Z. Effects of B on the Structure and Properties of Lead-Tin Bronze Alloy and the Mechanism of Strengthening and Toughening. Materials 2021, 14, 7806. https://doi.org/10.3390/ma14247806

Academic Editor: Filippo Berto

Received: 23 October 2021

Accepted: 21 November 2021

Published: 16 December 2021

Publisher's Note: MDPI stays neutral with regard to jurisdictional claims in published maps and institutional affiliations.

Copyright: (c) 2021 by the authors. Licensee MDPI, Basel, Switzerland. This article is an open access article distributed under the terms and conditions of the Creative Commons Attribution (CC BY) license (https:/ / creativecommons.org/licenses/by/ $4.0 /)$.

\begin{abstract}
High lead-tin bronze is widely used in the selection of wear-resistant parts such as bearings, bearing bushes, aerospace pump rotors, turbines, and guide plates because of its excellent wear resistance, thermal conductivity, fatigue resistance, and strong load-bearing capacity. At present, high lead-tin bronze is used as a material for bimetal cylinders, which cannot meet the requirements of high-strength, anti-wear in actual working conditions under high temperature, high speed, and heavy load conditions, and is prone to de-cylinder, cylinder holding, copper sticking, etc. The reason for the failure of cylinder body parts is that the strength of copper alloy materials is insufficient, the proportion of lead in the structure is serious, and the wear resistance of the material is reduced. Therefore, it has important theoretical significance and application value to carry out research on the comprehensive properties of high-performance lead-tin bronze materials and reveal the strengthening and toughening mechanism. In this paper, The ZCuPb20Sn5 alloy is taken as the main research object, and the particle size, microstructure, mechanical properties, and friction of lead particles in ZCuPb20Sn5 alloy are systematically studied after single addition of B in ZCuPb20Sn5 alloy liquid. This paper takes $\mathrm{ZCuPb} 20 \mathrm{Sn} 5$ alloy as the research object to study the effect of adding $\mathrm{B}$ on the morphology, microstructure, mechanical properties, and friction and wear properties of $\mathrm{ZCuPb} 20 \mathrm{Sn} 5$ alloy lead particles, and discusses the strengthening and toughening mechanism of $\mathrm{ZCuPb} 20 \mathrm{Sn} 5$ alloy under the action of $\mathrm{B}$, and prepares a double high-performance lead-tin bronze alloy for metal cylinders. The main research results are as follows: The addition of B elements has an obvious refining effect on the $\alpha(\mathrm{Cu})$ equiaxed grains and lead particles in ZCuPb20Sn5 alloy. The average size of lead particles decreases from $30.0 \mu \mathrm{m}$ to $24.8 \mu \mathrm{m}$ as the B content increases from $0 \mathrm{wt} . \%$ to $0.1 \mathrm{wt} . \%$. The reason for grain refinement is that B is easily concentrated at the grain boundary during the $\mathrm{ZCuPb} 20 \mathrm{Sn} 5$ alloy solidification process, which affects the diffusion of solute atoms at the solidification interface, inhibits the grain growth, refines the grain, and hinders the sinking and homogenizes distribution between dendrites of lead; the tensile strength of the ZCuPb20Sn5 alloy improves. Relatively without $\mathrm{B}$, when the addition of $\mathrm{P}$ is $0.1 \mathrm{wt} . \%$, the tensile strength is the largest at $244.04 \mathrm{MPa}$, which enhances $13 \%$; the maximum hardness gets $75.0 \mathrm{HB}$, which enhances $13.6 \%$, as well as elongation get the maximum value at $17.2 \%$. The main mechanism is that the addition of $\mathrm{B}$ forms a high melting point submicron $\mathrm{Ni}_{4} \mathrm{~B}_{3}$ phase in the lead-tin bronze alloy. The $\mathrm{Ni}_{4} \mathrm{~B}_{3}$ phase is dispersed in the matrix and strengthens the matrix. With the increase in B content (more than $0.1 \mathrm{wt} . \%$ ), the $\mathrm{Ni}_{4} \mathrm{~B}_{3}$ phase changes from sub-micron degree granular to micron degree block-like, and some defects such as shrinkage and porosity appear in the structure, resulting in a decrease in mechanical properties.
\end{abstract}

Keywords: lead-tin bronze; microstructure; grain refinement; mechanical properties; abrasion reduction performance 


\section{Introduction}

The room temperature mechanical properties and processing properties of copper alloys are improved [1] on adding trace rare earths to copper and copper alloys. However, the effect of deterioration and refinement is still immature, and the refinement system is not perfect. Therefore, further research on the mechanism of copper alloys is needed. At the same time, with the need for the production of high-strength and high-conductivity copper alloys and the recycling of waste copper, the role of boron in copper alloys [2,3] has attracted more and more attention. Studies have found that trace boron has the effect of refining grains in copper alloys. At the same time, it is concluded that the optimal addition amount of B is $0.01-0.1 \mathrm{wt} . \%$.

When Sun Liping studied the effects of $C e$ and $B$ on the structure and properties of HSn70-1 alloy, he found when the H70, HAl77-2, and HAl77-2As brass contain 0.049\%, $0.061 \%$, and $0.091 \%$ (mass fraction) of B, respectively, the grains are significantly refined and the tensile strength increases by $40-50 \mathrm{MPa}$. The yield strength is increased by $40-60 \mathrm{MPa}$, and the elongation and reduction of area are slightly reduced, but the degree of reduction is relatively low, and it does not affect the good plasticity and workability of the alloy $[4,5]$. After adding boron to the $70 \mathrm{Cu}-30 \mathrm{Ni}$ alloy, the strength of the alloy can be increased. Similarly, the plasticity is slightly reduced, but the corrosion resistance is improved to a certain extent, and the wear resistance is significantly improved [6]. As the content of B increases, the refinement effect increases. The B content is between $0.008 \%$ and $0.015 \%$, and the grain refinement and deterioration effect is the best when it is modified and poured after $10 \mathrm{~min}$ of heat preservation [7]. The addition of $B$ can suppress the grain-coarsening phenomenon that occurs in the material for a longer time or at a higher temperature [8]. When the addition amount of $\mathrm{B}$ is in the range of $0 \sim 0.15 \mathrm{wt} . \%$, with the increase in boron content, the dendrites in the CuNiMnFe alloy structure are gradually refined, and the distance between the secondary crystal arms is gradually reduced. When the addition amount of boron is $0.105 \mathrm{wt} . \%$, the lath eutectic $\beta$ phase basically disappears, the distance between the secondary arms of the dendrite in the alloy structure is the smallest, the as-cast hardness of the alloy reaches its peak, and the tensile strength of the alloy can reach $1130 \mathrm{MPa}[9]$.

Boron is an important strategic substance in the 21st century. It has active chemical properties at high temperatures and is often used as a degassing agent. The solid solubility of boron in $\mathrm{Cu}$ at room temperature is $0.06 \%$, and its limit is $0.53 \%$. Boron is an element with a small diameter that can be dissolved in copper both in an interstitial manner and in a replacement manner, and B and $\mathrm{Cu}$ cannot form any compound [10]. The main mechanism is that after adding B and P, P and B can also be concentrated in intragranular defects such as dislocations, occupying a large number of vacancies or interstitial positions, reducing the stacking fault energy of the alloy, and producing solid solution strengthening. At the same time, phosphorus and boron inhibit the grain boundary diffusion and are also beneficial to inhibit the grain boundary slip and crack initiation during creep. This delays the recovery of the alloy, inhibits the formation of recrystallized cores and the growth of crystals. Therefore, it is possible to refine the grains and purify the material, so that the alloy can obtain excellent high-strength comprehensive properties.

Because there have always been different opinions on the role of phosphorus in alloys, how to reasonably control the amount of phosphorus added to the alloy has become a difficult problem. On the basis of the existing research results, when the P element addition amount is controlled to $0.1 \mathrm{wt} . \%$, it becomes more and more important to improve the mechanical properties of the lead-tin bronze alloy by adding B element instead of high phosphorus.

Since there have always been different opinions on the role of phosphorus in alloys, how to reasonably control the amount of phosphorus added to the alloy has therefore become a problem. In this paper, based on the existing research results, the addition of $\mathrm{P}$ element is controlled to $0.1 \mathrm{wt} . \%$, and B is added instead of high phosphorus to improve the mechanical properties of the lead-tin bronze alloy. 


\section{Experimental Procedure}

\subsection{Preparation of As-Cast ZCuPb20Sn5 Alloy}

$\mathrm{ZCuPb} 20 \mathrm{Sn} 5-\mathrm{yB}$ alloy castings are smelted in a well-type resistance furnace and a 16\# graphite crucible. In ZCuPb20Sn5-yB alloy, $y=(0,0.01,0.05,0.1$ and 0.2$)$. The smelting furnace model is SG2-12-13, the rated voltage is $380 \mathrm{~V}$, and the rated temperature is $1300{ }^{\circ} \mathrm{C}$. Before smelting, raw materials, casting molds, and graphite rods for stirring are put in a $300{ }^{\circ} \mathrm{C}$ holding furnace in advance to preheat. During the smelting process, the temperature of the smelting furnace is adjusted to 900,1100 , and $1250{ }^{\circ} \mathrm{C}$ in sequence, and the furnace temperature is slowly increased. Electrolytic pure copper is the main raw material. Oxidation is inevitable during alloy smelting. In the smelting of lead-tin bronze, in order to prevent oxidation problems, the deoxidizer used in the experiment is a phosphor-copper alloy with a P content of $13.5 \mathrm{wt} . \%$. Due to the longer smelting process, the addition of alloys, and the number of steps, the deoxidation is carried out in two stages. When the first copper block is completely melted, $2 / 3$ of the phosphorous copper is added for preliminary deoxidation; after the addition of alloying elements is completed, the remaining $1 / 3$ of the phosphorous copper is added.

\subsection{Test and Analysis}

The microstructures of the as-cast $\mathrm{ZCuPb} 20 \mathrm{Sn} 5-0.1 \mathrm{P}-\mathrm{yB}$ were prepared, and then samples were taken to study the effect of $\mathrm{B}$ on the structure change of $\mathrm{ZCuPb} 20 \mathrm{Sn} 5$ alloy. The size of the metallographic analysis sample is basically $15 \mathrm{~mm} \times 15 \mathrm{~mm} \times 15 \mathrm{~mm}$. After the sample was corroded by ammonia, hydrogen peroxide, and water in a ratio of 1:1:3, the morphology was observed with the AXIO Scope.A1 metallographic microscope. And, using the grain evaluation software that comes with the device, the size and morphology of the lead particles in the ZCuPb20Sn5 alloy structure were evaluated. Analyze the size and morphological distribution of lead particles in the same field of view to determine whether there was segregation of lead particles in the organization. The morphology of the copper alloy was observed on Hitachi's new generation of thermal field emission scanning electron microscope SU5000, and combined with its built-in energy spectrometer function to perform energy spectrum analysis on the composition of the alloy structure and the composition of the precipitated phase, and at the same time stretched the fracture Scanning and data were also done using this device. A D/max-rB X-ray diffractometer of Rigaku (RIGAKU) was used to analyze the phase composition of the sample. The scanning speed was $6 \mathrm{deg} / \mathrm{min}$, and the scanning angle was 10 90 ${ }^{\circ}$. The Setaram Labsys synchronous thermal analyzer was used to detect and analyze the DSC experimental data, and measure the heat flow under different temperature conditions. The temperature measurement range is $20 \sim 1400{ }^{\circ} \mathrm{C}$, the heating rate is $5^{\circ} \mathrm{C} / \mathrm{min}$, and the cooling rate is $10^{\circ} \mathrm{C} / \mathrm{min}$. The copper alloy samples tested were of the size and shape of millet grains. The graph ICP-AES chemical element analyzer was used to detect the fluctuation of the chemical composition after each experiment to ensure the accuracy of the experimental data. Using the first-principles method based on density functional theory, the stability of the alloy was judged by the calculation results of the enthalpy of formation and binding energy, and the stability, hardness, and ductility of the second phase particles were simulated and predicted

The analysis of the tensile strength of ZCuPb20Sn5 alloy castings at room temperature was completed on the Instron 8801 static mechanical testing machine. Hardness testing was done in accordance with the national standard of "Standard Hardness Block Calibration" GB/T 231.1-2018 "Metallic Material Brinell Hardness Test Part 1: Test Method", using the HB-3000C electronic Brinell hardness tester to complete. 


\section{Results and Discussion}

\subsection{Microstructures}

3.1.1. The Change of Lead Particle Morphology in ZCuPb20Sn5 Alloy by Adding B

The microstructure of $\mathrm{ZCuPb} 20 \mathrm{Sn} 5-0.1 \mathrm{P}$ alloy samples with different $\mathrm{B}$ content is shown in Figure 1.

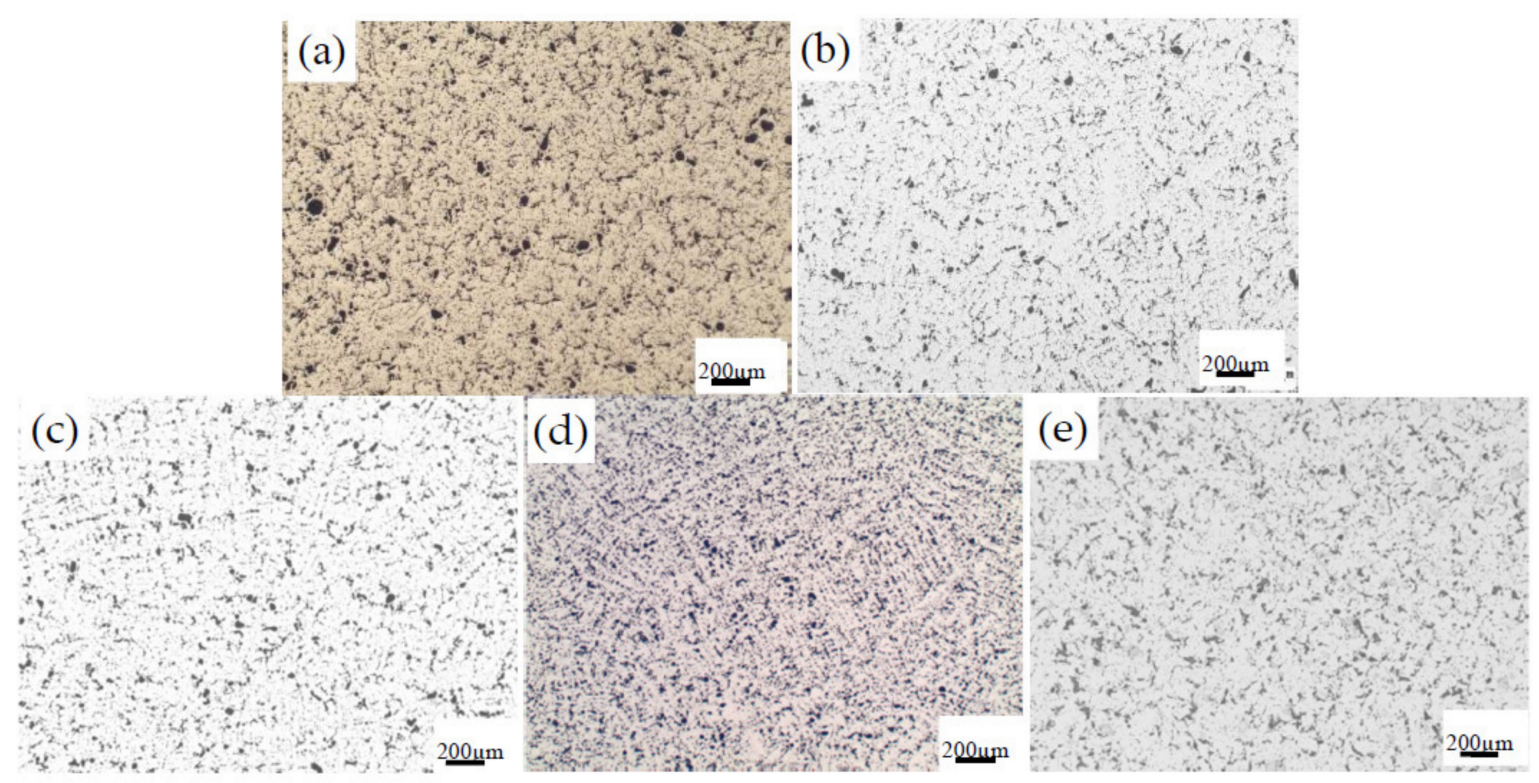

Figure 1. The microstructure of ZCuPb20Sn5-0.1P alloy with different content of B: (a) B 0 wt.\%, (b) B 0.01 wt.\%, (c) B 0.05 wt. $\%$, (d) B 0.1 wt. \%, (e) B 0.2 wt. $\%$.

Figure 1a-e are metallographic photos added $0 \mathrm{wt} . \%, 0.01 \mathrm{wt.} \%, 0.05 \mathrm{wt.} \%, 0.1 \mathrm{wt.} \%$, $0.2 \mathrm{wt} . \% \mathrm{~B}$, respectively, to ZCuPb20Sn5-0.1P alloy. It can be seen that the lead particles in the alloy structure tend to be refined after adding boron from the figure. Specific changes can be analyzed in conjunction with Figure 2.
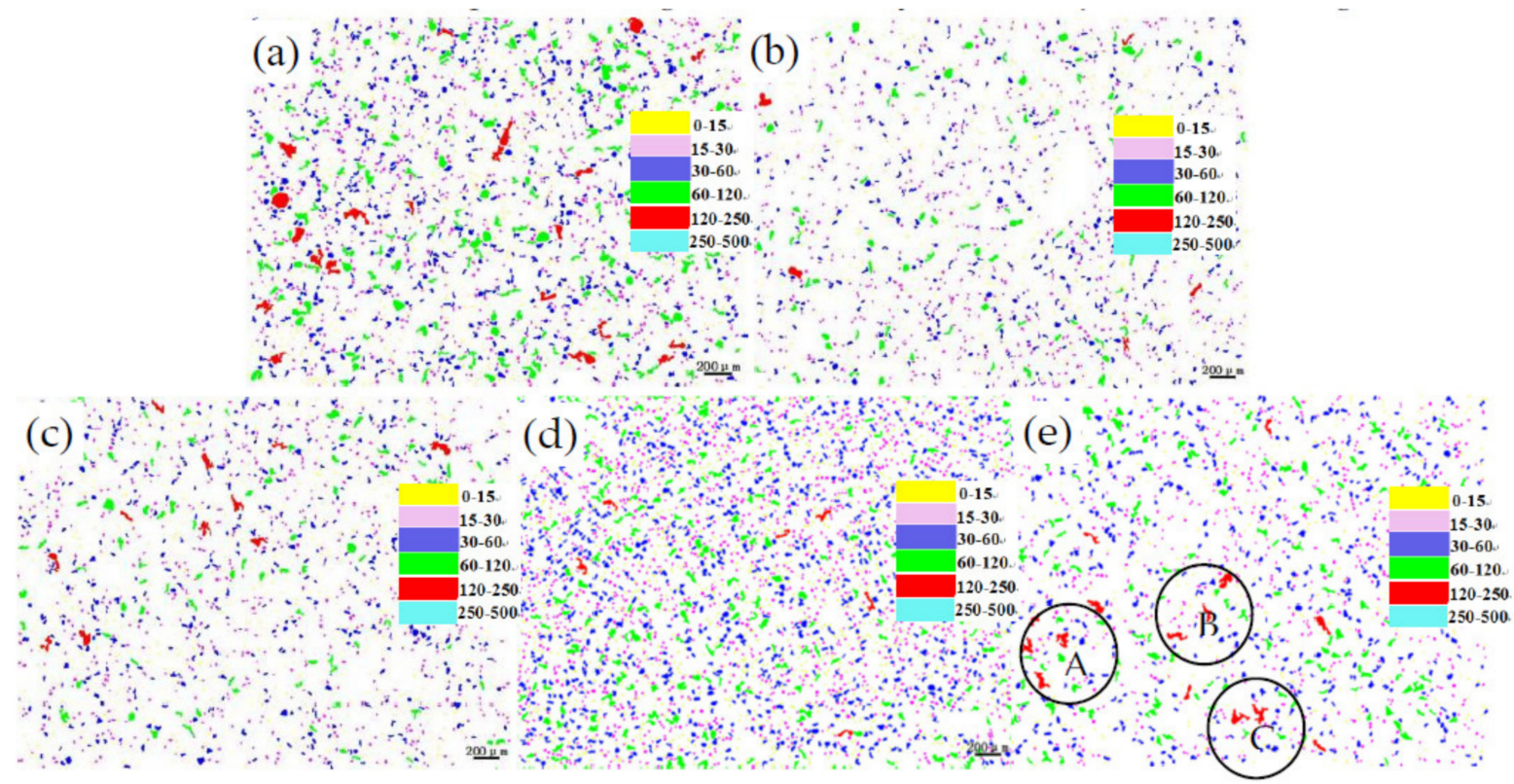

Figure 2. Changes of lead particle size distribution in ZCuPb20Sn5 alloy with different P contents: (a) B 0 wt.\%, (b) B 0.01 wt. \%, (c) B 0.05 wt. \%, (d) B 0.1 wt. \%, (e) B 0.2 wt. $\%$. 
Figure 2a-e is respectively shows the change in lead particles and distribution map of lead particles in ZCuPb20Sn5-0.1P alloy after adding different content of boron ( $0 \mathrm{wt} . \%$, 0.01 wt. $\%, 0.05$ wt. $\%, 0.1$ wt. $\%$, and 0.2 wt. $\%$ ). From the data in Figure 2, it can be seen that the amount of B added is between $0.01 \% \mathrm{wt} . \%$ and $0.2 \% \mathrm{wt} . \%$, and the average size of lead particles is less than $250 \mu \mathrm{m}$. Figure 2a shows that when B is not added, there are 22 lead particles in the range of $120-250 \mu \mathrm{m}$ and it is reduced to $14 \mathrm{when} 0.01 \mathrm{wt} . \% \mathrm{~B}$ is added, as shown in Figure $2 \mathrm{~b}$. When the content of $B$ is added to $0.1 \mathrm{wt} . \%$, as shown in Figure $2 \mathrm{~d}$, the lead particles in the size range of $120-250 \mu \mathrm{m}$ are reduced to 9 pieces. Compared with other types of B content, $0.1 \mathrm{wt}$.\% of lead is added. In the case of particles, the lead particles in the two ranges of $0-30 \mu \mathrm{m}$ and $15-30 \mu \mathrm{m}$ are the most. With the increase in B content, the lead particles in the size range of $60-120 \mu \mathrm{m}$ gradually decrease, from 192 without $B$ added to 98 when B $0.1 \mathrm{wt} . \%$ is added.

It shows that the addition of $B$ can refine the lead particles, but when the content of $B$ increases to $0.2 \mathrm{wt} . \%$, as shown in Figure 2e, the size of the lead particles increases, and the shape gradually changes from spherical to irregular.

From the change in average diameter of the lead particles (Table 1), it can be seen that after adding $\mathrm{B}$ to the alloy liquid $\mathrm{ZCuPb} 20 \mathrm{Sn} 5$, the lead particles are obviously refined. With the addition of $B$, the average diameter of lead particles in the alloy is refined from $30.0 \mu \mathrm{m}$ when $\mathrm{B}$ is not added to $24.8 \mu \mathrm{m}$ when $\mathrm{B}$ is added $0.1 \%$, which is $17.3 \%$. However, as the $\mathrm{B}$ content continues to increase, the lead particles have a tendency to grow again.

Table 1. Data table of average diameter of lead particles after adding different elements to lead-tin bronze.

\begin{tabular}{cc}
\hline Element Content (wt.\%) & Average Diameter of Lead Particles $(\mu \mathrm{m})$ \\
\hline B: 0.00 & 30.0 \\
B: 0.01 & 28.8 \\
B: 0.05 & 26.8 \\
B: 0.10 & 24.8 \\
B: 0.20 & 28.6 \\
\hline
\end{tabular}

It can be clearly seen from Figure 3 that the addition of boron can refine the lead particles and make the large lead particles smaller and more uniform. Among them, the small particles (lead particles in the range of $\leqq 30 \mu \mathrm{m}$ ) increase with the increase of B content. As the B content increases, the large particles (lead particles in the range of $30 \mu \mathrm{m}$ ) decrease with the increase of B content. But when the content of B exceeds $0.2 \mathrm{wt} . \%$, although the small particles increase, the large particles in the range of 30 120 also increase. From the perspective of the change form of lead particles, the addition of element $B$ cannot be greater than $0.2 \mathrm{wt} . \%$.

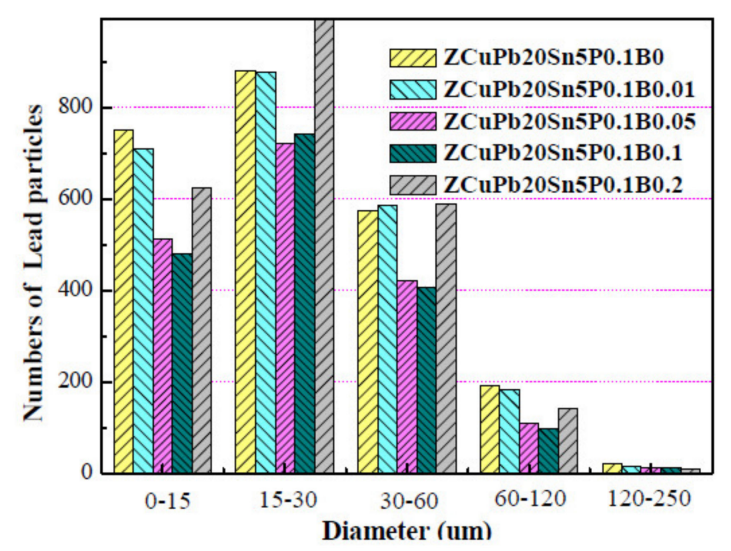

Figure 3. Lead particle number distribution map of ZCuPb20Sn5-yB alloy. 
The influence of the size and number of lead particles on the organization and performance will be described in detail in the following organization performance analysis section. However, the size of the lead particles is too large and unevenly distributed, which will cause the organization to deteriorate. Therefore, reduce the size of the lead particles at the same time to make it evenly distributed is one of the purposes of its alloying.

At the same time, when B is not added, there are lead particles in the range of $60 \sim 500 \mu \mathrm{m}$. After adding B, the large particles are mainly concentrated in the range of $120 \sim 250 \mu \mathrm{m}$, and the number is small. After adding B $0.01 \mathrm{wt} . \%$, the number of lead particles in this range is 14 . With the increase of $\mathrm{B}$ content, the lead particles tend to be refined, but the effect will be weakened after adding more.

The main reasons for the changes in lead particles:

1. When B is added to the copper liquid, the solidification range of the copper alloy is shortened, and the time for the lead particles to sink and gather, so the lead particles become smaller and evenly distributed.

2. The addition of $B$ refines the crystal grains and prevents the sinking of lead.

3. The addition of $B$ reflects the harmful impurities in the liquid, removes harmful gases such as oxygen and hydrogen, and makes the lead particles pure, fine, and evenly distributed.

4. As the content of B continues to increase (more than $0.1 \%$ ), the form of the second phase with high melting point will change from granular to massive, or even large lumps, which will reduce the fluidity of the alloy liquid and cause the lead particles to gather and grow up.

3.1.2. Change of $\alpha$ Structure Morphology in ZCuPb20Sn5-0.1P-yB Alloy Structure

(1) Macro Organizational Changes

After sampling, polishing, and etching the castings after casting, observe their macroscopic appearance, as shown in Figure 4.
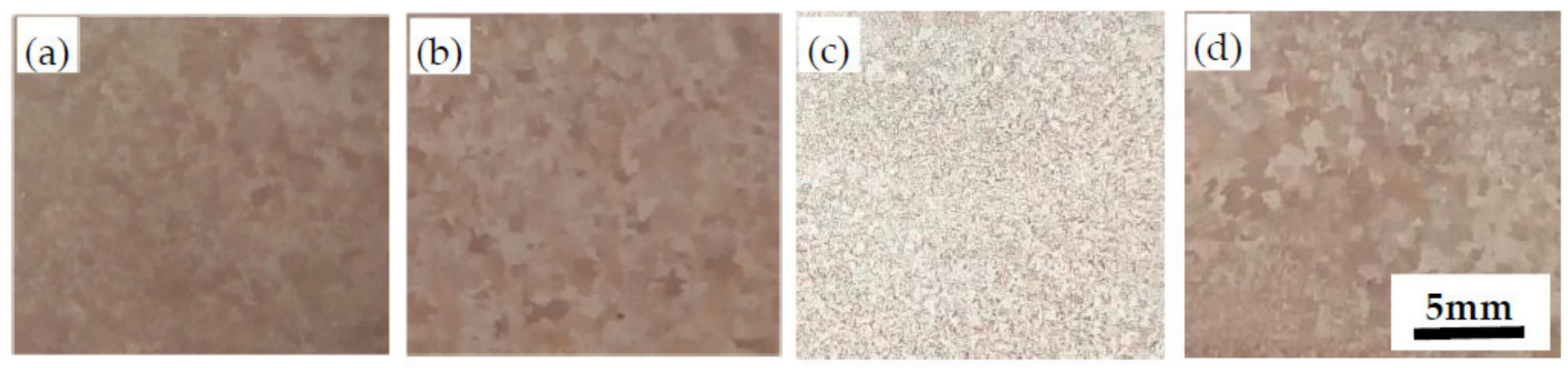

Figure 4. Macrostructure of the ZCuPb20Sn5Ni3-0.1P-yB alloy. (a) B = 0.0 wt.\%; (b) B = 0.05 wt.\%; (c) B = 0.1 wt.\%; (d) $\mathrm{B}=0.2 \mathrm{wt} . \%$.

Figure $4 \mathrm{a}-\mathrm{d}$ is photos of the macrostructure of the alloy with B (0.01 wt.\% 0.2 wt.\%). It can be seen from the figure that the addition of $B$ refines the $\alpha$ grains. When $0.1 \mathrm{wt} . \%$ of $B$ is added, the $\alpha$ grains are the smallest, and the content of B continues to increase, the grains begin to grow.

(2) Microstructure

After corrosion of ZCuPb20Sn5 alloy samples with different B content (0 wt.\%, $0.01 \mathrm{wt} . \%, 0.05 \mathrm{wt} . \%, 0.1 \mathrm{wt.} \%$ and $0.2 \mathrm{wt} . \%)$, they were observed under a scanning electron microscope to obtain the microstructure of the sample, as shown in Figure 5. 

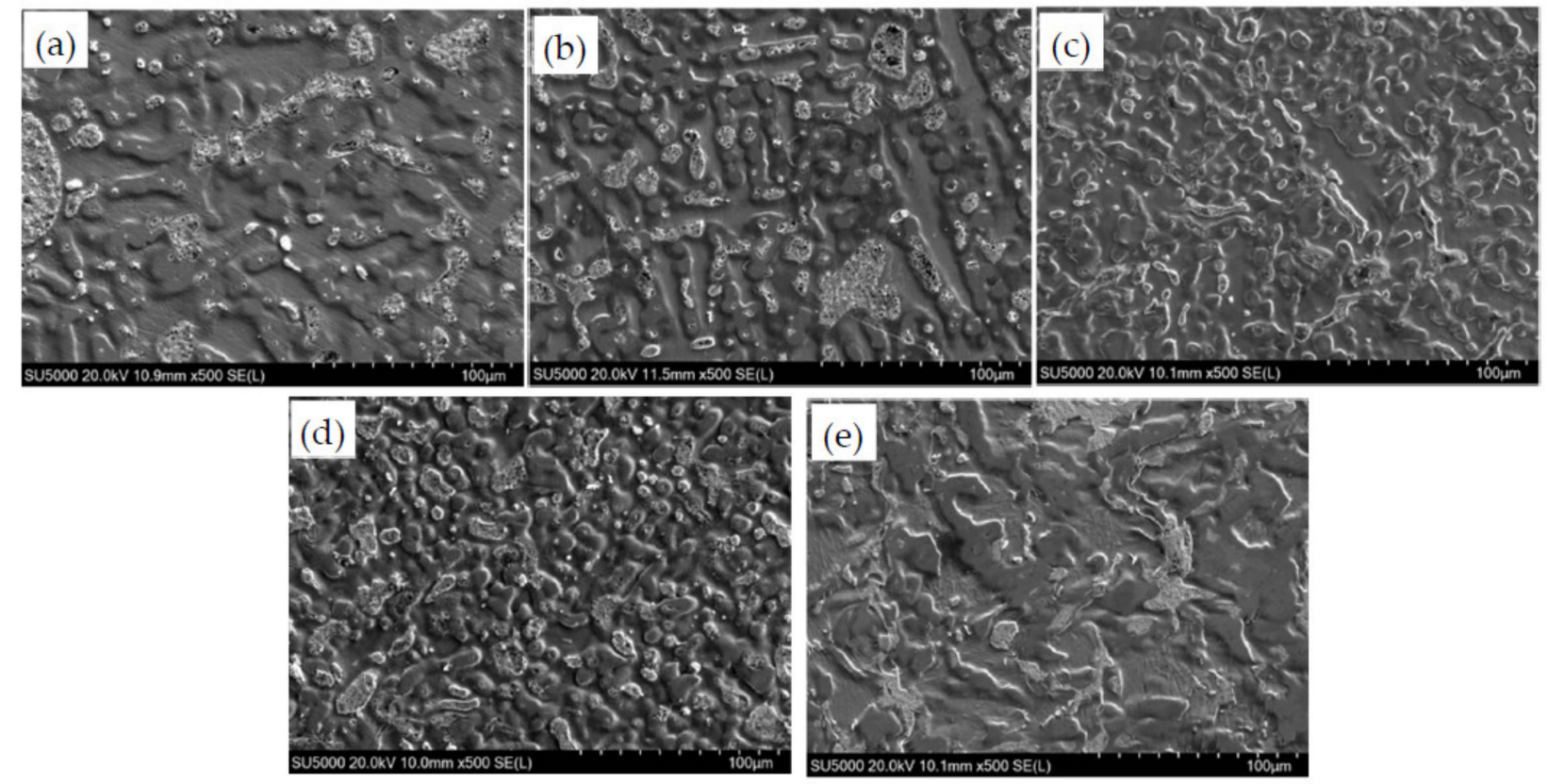

Figure 5. BSE microstructure of the ZCuPb20Sn5-0.1P-yB-zY alloy at 500 times. (a) B = 0 wt. $\%$; (b) B = 0.01 wt. $\%$; (c) B = 0.05 wt. $\%$; (d) B = 0.1 wt. $\%$; (e) B = 0.2 wt. $\%$.

The content of trace element $B$ is different, and the dendrite morphology is different in the area. From Figure $5 \mathrm{a}-\mathrm{e}$, it can be seen that the $\alpha$ dendrites are distributed in equiaxed crystals, and the crystal axis is refined with the increase of B content. However, when the content of B is greater than $0.1 \mathrm{wt} . \%$, as shown in Figure 5e, the dendritic structure changes, from equiaxed crystals to disordered chrysanthemums, and the crystal arms become thicker. In the four different solutions when the B content is less than $0.2 \mathrm{wt} . \%$, the thickest dendrite arm is about $20 \mu \mathrm{m}$, and the average length is between $20-60 \mu \mathrm{m}$. With the increase of B content, the number of dendrite arms in the area increases, and the dendrite arms become finer. When the $\mathrm{B}$ content is increased to $0.1 \mathrm{wt} . \%$, the dendrite size in the area is on average between 10-15 $\mu \mathrm{m}$. When the content of $B$ increased to $0.2 \mathrm{wt} . \%$, the organization changed, and the original dendrites began to distribute in the form of chrysanthemums.

\subsubsection{Analyze the Reasons for the Refinement of Alpha Phase and Lead Particles by B}

Figure 6 shows the relationship between heat flow and sample temperature during the cooling process of $\mathrm{ZCuPb} 20 \mathrm{Sn} 5$ and $\mathrm{ZCuPb} 20 \mathrm{Sn} 5 \mathrm{~B} 0.1$ alloys. The black line represents the curve of ZCuPb20Sn5P0.1 alloy, and the red represents the curve of ZCuPb20Sn5B0.1.

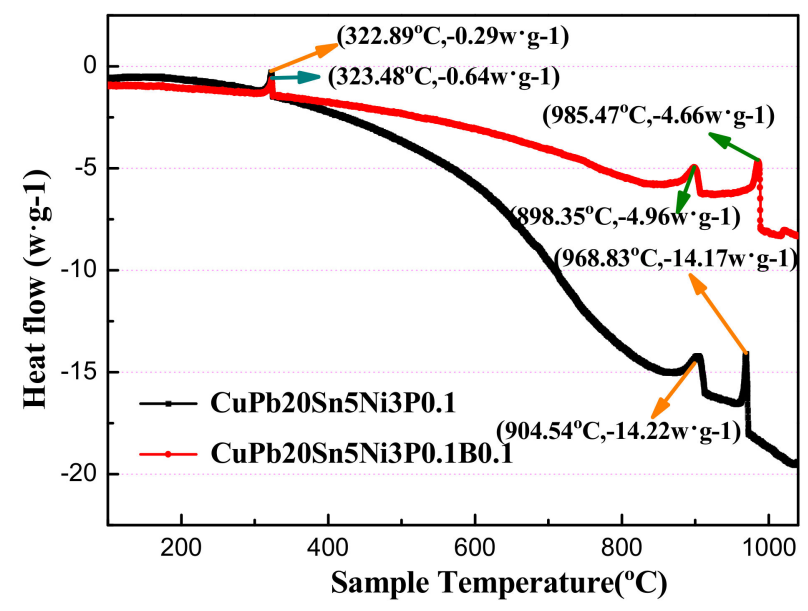

Figure 6. DSC of the ZCuPb20Sn5P0.1-xB alloy. 
It can be seen from Figure 6 that the overall curve has three obvious exothermic peaks during the cooling process. The $\mathrm{ZCuPb} 20 \mathrm{Sn} 5 \mathrm{~B} 0.1$ alloy has four exothermic peaks. It corresponds to the three peaks of the ZCuPb20Sn5 alloy. The first exothermic peak of the $\mathrm{ZCuPb} 20 \mathrm{Sn} 5$ alloy is at $\left(968.83^{\circ} \mathrm{C},-14.17 \mathrm{w} \cdot \mathrm{g}^{-1}\right)$, while the second exothermic peak of the $\mathrm{ZCuPb} 20 \mathrm{Sn} 5 \mathrm{~B} 0.1$ alloy is at $\left(985.47^{\circ} \mathrm{C},-4.66 \mathrm{w} \cdot \mathrm{g}^{-1}\right)$, where are the precipitated phases of the copper matrix. The temperature of the copper matrix phase is reduced by $17^{\circ} \mathrm{C}$ in the first place. The temperature of the second eutectoid $\left(\alpha+\delta+\mathrm{Ni}_{3} \mathrm{P}\right)$ is reduced by $11^{\circ} \mathrm{C}$. The solidification temperature range of the copper phase is shortened, and the large lead particles are distributed evenly among the dendrites before they can gather and grow up. With the addition of B, the intragranular structure is refined, and the lead particles gradually change from large dots to small spheres, which improves the degree of lead segregation.

The second peak of the ZCuPb20Sn5 alloy and the third exothermic peak of the ZCuPb20Sn5B0.1 alloy are at $\left(904.54{ }^{\circ} \mathrm{C},-14.22 \mathrm{w} \cdot \mathrm{g}^{-1}\right)$ and $\left(893.35{ }^{\circ} \mathrm{C},-4.96 \mathrm{w} \cdot \mathrm{g}^{-1}\right)$, respectively. According to the above phase diagram, it is judged that this place is the precipitation point of $\left(\alpha+\delta+\mathrm{Ni}_{3} \mathrm{P}\right)$ eutectoid. The third peak of the $\mathrm{ZCuPb} 20 \mathrm{Sn} 5$ alloy and the fourth exothermic peak of the ZCuPb20Sn5B0.1 alloy are at $\left(323.48{ }^{\circ} \mathrm{C},-0.64 \mathrm{w} \cdot \mathrm{g}^{-1}\right)$ and $\left(322.89{ }^{\circ} \mathrm{C},-0.29 \mathrm{w} \cdot \mathrm{g}^{-1}\right)$, respectively. This is the peak point of the precipitation phase of lead particles. The melting point of lead is $328^{\circ} \mathrm{C}$, and the crystallization point of lead is reduced by 4 to $5^{\circ} \mathrm{C}$. After adding boron, as shown by the arrows in Figure 6 , the size of the lead particles is different, resulting in a slightly different precipitation temperature of the lead particles - the lead particles become smaller, and the peak intensity gradually weakens.

The first exothermic peak of the ZCuPb20Sn5B0.1 alloy has a small peak at about $1025^{\circ} \mathrm{C}$. According to the previous $\mathrm{Cu}-\mathrm{Ni}$ phase diagram, it can be seen that the melting points of $\mathrm{Ni}_{2} \mathrm{~B}$ and $\mathrm{Ni}_{3} \mathrm{~B}$ are $1125{ }^{\circ} \mathrm{C}$ and $1156^{\circ} \mathrm{C}$, respectively. Since the melting point of $\mathrm{Ni}_{4} \mathrm{~B}_{3}$ is $1018{ }^{\circ} \mathrm{C}$, this point is the precipitation point of $\mathrm{Ni}_{4} \mathrm{~B}_{3}$ phase, which is consistent with the results of XRD data. During the solidification of the alloy material, the $\mathrm{Ni}_{4} \mathrm{~B}_{3}$ phase is first precipitated at $1025^{\circ} \mathrm{C}$. Since the number of this phase is extremely small, the peak value is particularly small. Subsequently, this phase is formed before the solidification of copper, as a solute component, which is dissolved in the copper alloy liquid. As the solidification of the copper alloy is precipitated at $968 \sim 985^{\circ} \mathrm{C}$, the peak value is relatively large, and the copper matrix phase begins to precipitate. Then, when the temperature was lowered to $898 \sim 904{ }^{\circ} \mathrm{C}$, the eutectoid $\left(\alpha+\delta+\mathrm{Ni}_{3} \mathrm{P}\right)$ precipitated, and the precipitation temperature of the lead particles was $323^{\circ} \mathrm{C}$.

The $\mathrm{Ni}_{4} \mathrm{~B}_{3}$ phase is formed before the solidification of copper, and as the copper alloy solidifies and precipitates, it is repelled by the copper grains and concentrated at the grain boundary, which directly affects the diffusion of solute atoms at the solidification interface, the growth curvature of the interface, and the re-nucleation occurrence and so on, thereby inhibiting the growth of grains and achieving the purpose of grain refinement. The main refinement effect is to limit the growth mechanism.

\subsubsection{Microstructure and Phase Structure of the ZCuPb20Sn5-yB Alloy}

(1) XRD Analysis

In order to judge the phases in the structure more accurately, further analysis of the alloy is needed. Figure 7 is the XRD data diagram of the alloy after adding B, and Figure 7a is the $\mathrm{XRD}$ data graph of the $\mathrm{ZCuPb} 20 \mathrm{Sn} 5-0.1 \mathrm{~B}$ alloy, Figure $7 \mathrm{~b}$ is the XRD data graph of alloy ZCuPb20Sn5-0.2B. 

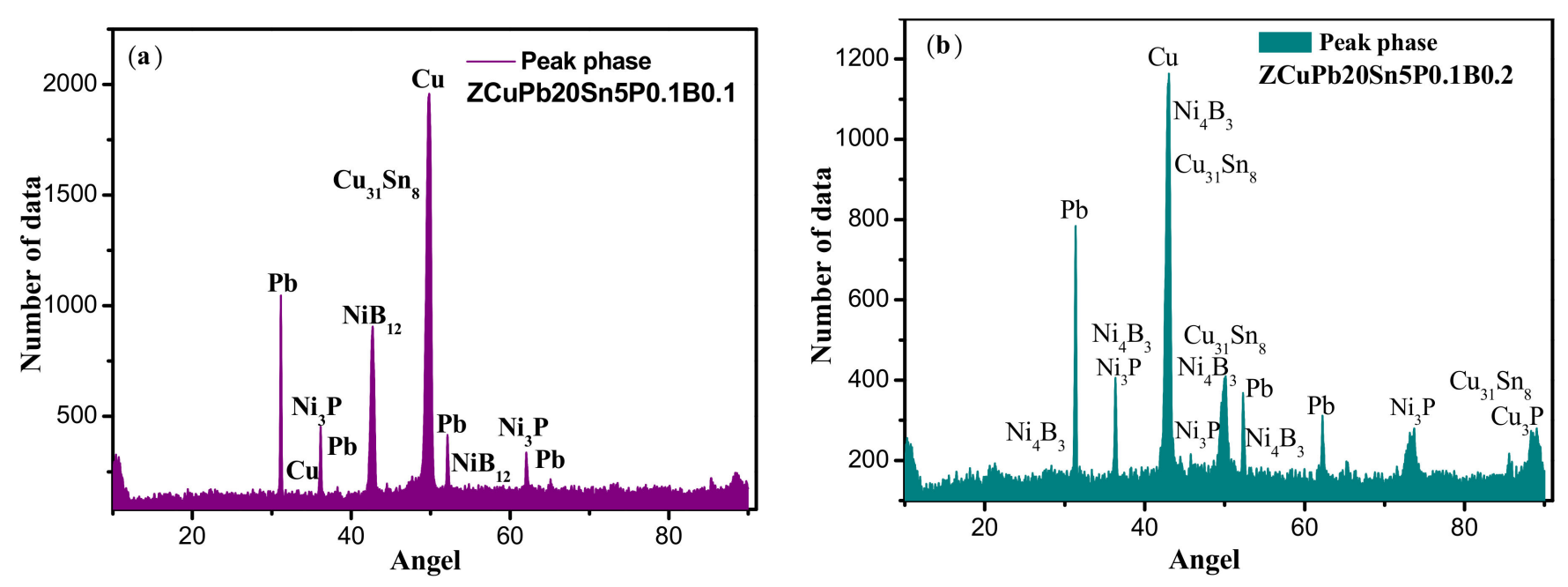

Figure 7. XRD analysis of the ZCuPb20Sn5-xB alloy. (a) ZCuPb20Sn5-0.1B; (b) ZCuPb20Sn5-0.2B.

It can be seen from Figure 9 that a series of main peaks clearly appear in the XRD spectrum, which are consistent with the face-centered cubic (FCC) solid solution $\alpha$ phase (Cu-based) and represent the diffraction peaks of the copper matrix. By analyzing the XRD data, it can be seen that when the addition amount of $B$ is $0.1 \mathrm{wt} . \%$, the second phase of $P$ is mainly the $\mathrm{Ni}_{3} \mathrm{P}$ phase, which appears at $36.418^{\circ}(031)$ and the peak value is relatively strong. The second phase of $\mathrm{B}$ is mainly $\mathrm{NiB}_{12}$ phase; this phase is less, and this phase has a coherent relationship with the copper matrix phase. The content of phosphorus and nickel is different, and the atomic ratio of nickel and boron is different. In the XRD diffraction pattern of alloy $\mathrm{ZCuPb} 20 \mathrm{Sn} 5-0.2 \mathrm{~B}$, the $\mathrm{NiB}_{12}$ phase is basically not detected, but the diffraction peak of $\mathrm{Ni}_{4} \mathrm{~B}_{3}$ phase appears.

(2) Organizational Structure

The ZCuPb20Sn5-yB alloy was analyzed by SEM and EDS, and the crystal structure of the mesophase that may be formed by different $\mathrm{B}$ in the alloy $\mathrm{ZCuPb} 20 \mathrm{Sn} 5$ was analyzed, as shown in Figures 8 and 9.

Figures 8 and 9 are the phase structure diagrams of alloy ZCuPb20Sn5-yB. Figure $8 \mathrm{a}-\mathrm{c}$ are respectively SEM images of the ZCuPb20Sn5-yB alloy $(\mathrm{y}=0 \mathrm{wt} . \%, 0.01 \mathrm{wt} . \%$ and $0.05 \mathrm{wt} . \%)$. Figure $8 \mathrm{~d}-\mathrm{j}$ are the circles A, B, C, D, E, F, and G in the figure. The EDS data graph is pointed by the arrow. Figure $9 a, b, g$ are the SEM images of the $\mathrm{ZCuPb20Sn5-0.1P-}$ $\mathrm{yB}$ alloy $(\mathrm{y}=0.1 \mathrm{wt} . \%$ and $0.2 \mathrm{wt} . \%)$, respectively. Figure $8 \mathrm{c}-\mathrm{f}, \mathrm{h}-\mathrm{j}$ is the arrows in the circles of $\mathrm{A}, \mathrm{B}, \mathrm{C}, \mathrm{D}$, and $\mathrm{E}$ in the figure graph of EDS data.

It can be seen from the figure that when the content of $B$ added is less than $0.1 \mathrm{wt} . \%$, the second phase $\mathrm{Cu}_{3} \mathrm{P}$ is not found in the structure, except for the matrix $\alpha$ phase, $\mathrm{Pb}$ phase, and $(\alpha+\delta)$ phase. From the SEM of Figure 8 , the small black lumps indicated by A, $\mathrm{D}$, and $\mathrm{E}$, and the corresponding EDS data Figure $8 \mathrm{~d}, \mathrm{~g}$, $\mathrm{h}$ confirm that it may be the $\mathrm{CuNi}_{2} \mathrm{P}$ phase, and in this range, 10 similar particles are selected for measurement and the average value is obtained, and it is concluded that the phase is close to the $\mathrm{CuNi}_{2} \mathrm{P}$ phase. White irregular spherical particles are $\mathrm{Pb}$ phase particles, and off-white block. From the SEM of Figure $8 \mathrm{~b}, \mathrm{c}$ indicate the off-white block and island block structure, and the corresponding EDS data in Figure $8 \mathrm{e}, \mathrm{f}$, it can be confirmed that this phase is a $\delta$ phase. 

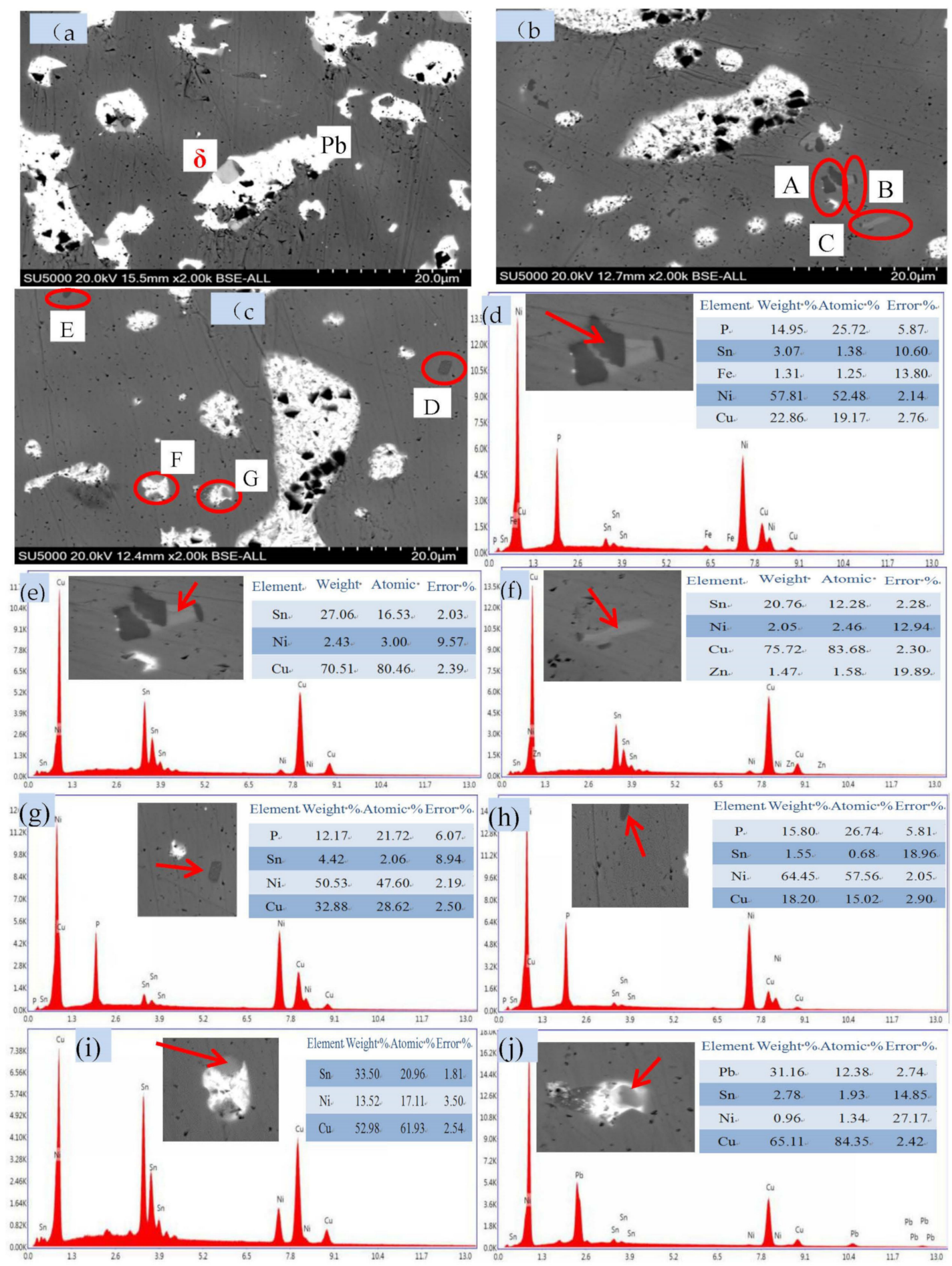

Figure 8. The phase microstructure of the ZCuPb20Sn5-0.1P-yB alloy. (a) SEM of alloy with 0 wt.\% B; (b) SEM of alloy with 0.01 wt.\% B; (c) SEM of alloy with 0.05 wt.\% B; (d) EDS of A; (e) EDS of B; (f) EDS of C; (g) EDS of D; (h) EDS of E; (i) EDS of F; (j) EDS of G.

When the addition amount of B is greater than or equal to $0.1 \mathrm{wt} . \%$, as shown in Figure 9, the phase structure in the ZCuPb20Sn5-0.1P-yB alloy structure changes, and the $\delta$ phase in the ZCuPb20Sn5-0.1P-yB alloy structure decreases. There is also a black-gray flaky boron phase in the structure. After EDS composition analysis, the ZCuPb20Sn5-0.1B alloy is shown at A and C in Figure 9 SEM, corresponding to the EDS images (a) and (c). It is known that the lamella structure is a phase of nickel and boron. According to the 
ratio of atomic number, it can be preliminarily judged that this item is a $\mathrm{Ni}_{2} \mathrm{~B}$ phase. From the positions B and D in Figure 8 SEM, corresponding to the EDS diagrams (b) and (d), it can be seen that the small black dots are mainly the solid solution phase of boron and copper, because according to the phase diagram, it can be seen that boron and copper has no binary alloy phase, and the boron phase is mainly the $\mathrm{NiB}_{12}$ phase. When the content of boron increases, the boron-nickel phase changes, as shown in the EDS picture $9(\mathrm{~h})$ corresponding to E in the SEM of Figure 9, the block shape becomes bar shape, and the structure becomes $\mathrm{Ni}_{3} \mathrm{~B}$.
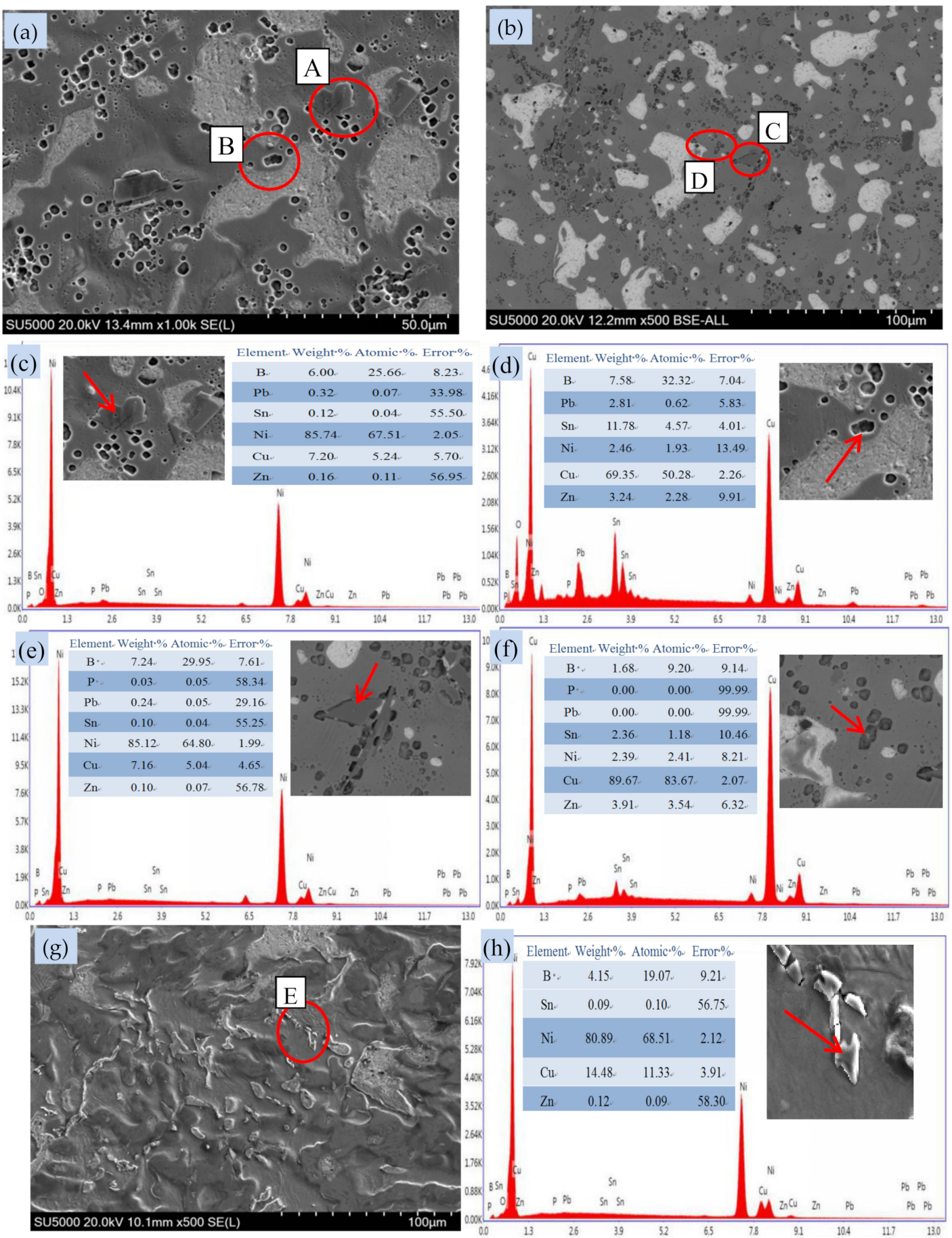

Figure 9. Microstructure of alloy ZCuPb20Sn5Ni3-0.1P-yB phase. (a) SEM of alloy with 0.1 wt.\% B; (b) SEM of alloy with 0.2 wt.\% B; (c) EDS of A; (d) EDS of B; (e) EDS of C; (f) EDS of D; (g) SEM of alloy with 0.2 wt.\% B; (h) EDS of E. 


\section{(3) Crystal Structure Analysis}

From the above analysis, it can be known that the $\mathrm{Ni}_{4} \mathrm{~B}_{3}$ phase may be formed in the $\mathrm{ZCuPb} 20 \mathrm{Sn} 5-\mathrm{yB}$ alloy. The first-principles simulation software is used to simulate and calculate the $\mathrm{Ni}_{4} \mathrm{~B}_{3}$ phase in the $\mathrm{ZCuPb} 20 \mathrm{Sn} 5$-yB alloy; using the density functional theory Cambridge Serial Total Energy Package (Castep) [11] package module, periodic boundary condition, the crystal wave function is expanded by the plane wave group [12]. The plane wave cut-off energy Ecut is $540.0 \mathrm{eV}$, the number of K-point grids for the $\mathrm{Ni}_{3} \mathrm{P}$ phase is $6 \times$ $6 \times 12$, and the $\mathrm{Cu} 3 \mathrm{P}$ phase is $10 \times 10 \times 10$. The plane wave truncation energy is $500 \mathrm{eV}$, and the number of $\mathrm{K}$-point grids of the $\mathrm{Ni}_{4} \mathrm{~B}_{3}$ phase is $10 \times 12 \times 8$. The Broyden Flecher Goldfarb Shanno (BFGS) method [13] is used for geometric optimization to obtain their local stable structures. The simulated $\mathrm{Ni}_{4} \mathrm{~B}_{3}$ phase structure model is shown in Figure 10, and the simulation data results are shown in Table 2.

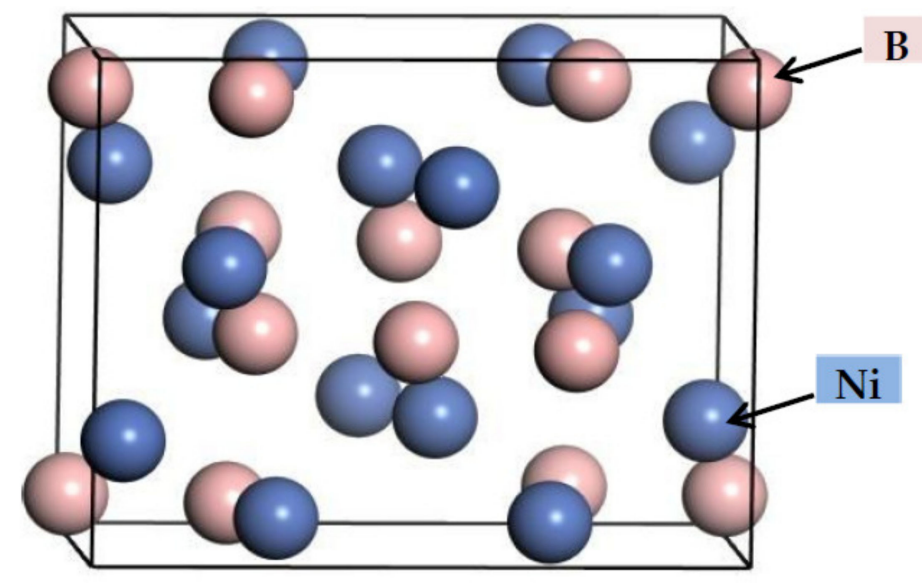

Figure 10. Crystal structure of $\mathrm{Ni}_{4} \mathrm{~B}_{3}$ phases.

Table 2. Crystal structure parameters of $\mathrm{Ni}_{4} \mathrm{~B}_{3}$ phases.

\begin{tabular}{|c|c|c|c|c|c|c|c|c|c|}
\hline \multirow{2}{*}{ Phase } & \multirow{2}{*}{$\begin{array}{c}\text { Group } \\
\text { (No.) }\end{array}$} & \multirow{2}{*}{$\begin{array}{l}\text { Crystal } \\
\text { Structure }\end{array}$} & \multicolumn{3}{|c|}{ Lattice Constant (̊̊) } & \multirow{2}{*}{ Densityg $/ \mathrm{cm}^{3}$} & \multirow{2}{*}{$\begin{array}{l}\text { Volume } \\
\mathrm{cm}^{3}\end{array}$} & \multirow{2}{*}{$\begin{array}{l}\text { Enthalpy of } \\
\text { Formation } \\
\text { eV/Atom }\end{array}$} & \multirow{2}{*}{$\begin{array}{c}\text { Binding } \\
\text { Energy } \\
\text { eV/Atom }\end{array}$} \\
\hline & & & $\mathbf{a}$ & $\mathbf{b}$ & c & & & & \\
\hline $\mathrm{Ni}_{4} \mathrm{~B}_{3}$ & $\mathrm{I}-4$ & $\begin{array}{l}\text { Triclinic } \\
\text { system }\end{array}$ & 6.392 & 4.913 & 7.868 & 7.348 & 241.6 & -0.599 & -6.247 \\
\hline $\mathrm{Ni}_{3} \mathrm{P}$ & $\mathrm{I}-4$ & Quartet & 8.966 & 8.966 & 4.384 & 7.808 & 352.4 & -0.510 & -5.909 \\
\hline $\mathrm{Cu}_{3} \mathrm{P}$ & $\mathrm{P}_{6}{ }_{3} \mathrm{CM}$ & Six parties & 6.971 & 6.971 & 7.183 & 7.305 & 302.3 & -0.041 & -4.158 \\
\hline
\end{tabular}

From the data in Table 2, we can see that the $\mathrm{Ni}_{4} \mathrm{~B}_{3}$ phase has a triclinic crystal structure. The density is close to that of the $\mathrm{Cu}_{3} \mathrm{P}$ phase, and the volume is smaller than that of $\mathrm{Cu}_{3} \mathrm{P}$ and $\mathrm{Ni}_{3} \mathrm{P}$. In addition, after calculation, the absolute values of the formation enthalpy and binding energy of $\mathrm{Ni}_{4} \mathrm{~B}_{3}$ phase are greater than $\mathrm{Cu}_{3} \mathrm{P}$ and $\mathrm{Ni}_{3} \mathrm{P}$. With the larger absolute value, the easier it is to form and the more stable after formation. Therefore, $\mathrm{Ni}_{4} \mathrm{~B}_{3}$ is easier to form than $\mathrm{Cu}_{3} \mathrm{P}$ and $\mathrm{Ni}_{3} \mathrm{P}$, and more stable after formation.

The addition of $\mathrm{B}$ has an obvious refinement effect on the structure of ZCuPb20Sn5 alloy, which can refine the $\alpha(\mathrm{Cu})$ equiaxed crystal and reduce the lead particles. When B is not added, the average diameter of lead particles is $30.0 \mu \mathrm{m}$, and when $0.1 \mathrm{wt} . \% \mathrm{~B}$ is added, it is $24.8 \mu \mathrm{m}$, which is $17.3 \%$ thinner. The reason for the grain refinement is that when the $\mathrm{ZCuPb} 20 \mathrm{Sn} 5$ alloy is solidified, boron is easily enriched at the grain boundary, which affects the diffusion of solute atoms at the solidification interface, inhibits the growth of grains, refines the grains, prevents the sinking of lead, and distributes it evenly between the dendrites. When the amount of $\mathrm{B}$ added is $0.1 \mathrm{wt}$., the $\mathrm{Ni}_{4} \mathrm{~B}_{3}$ phase is formed in the alloy. 
3.2. The Effect of B on the Mechanical Properties of Lead-Tin Bronze Alloys, and the Strengthening and Toughening Mechanism

\subsubsection{Hardness Analysis}

It can be seen from the bar (graph 11a) that the hardness of the ZCuPb20Sn5 alloy increases with the increase in boron. From not adding $B$ to $0.01 \mathrm{wt} . \%$, the hardness increased $1 \mathrm{HB}$. In the process of increasing from B $0.01 \mathrm{wt} . \%$ to B $0.05 \mathrm{wt} . \%$, the hardness increased $6.56 \mathrm{HB}$, and the increase rate was $9.95 \mathrm{wt} . \%$. In the process of increasing from B $0.05 \mathrm{wt} . \%$ to $\mathrm{B} 0.1 \mathrm{wt} . \%$, the hardness increased by about $1.5 \mathrm{HB}$, and the increase was not large. When the B content is $0.1 \mathrm{wt} . \%$, the hardness is $75 \mathrm{HB}$. When the B content is $0.2 \mathrm{wt} . \%$, the hardness value drops to $74.2 \mathrm{HB}$. Judging from the hardness values of several groups of different contents of $B$, when $0.1 \mathrm{wt} . \%$ of $B$ is added, the hardness value is the largest. However, it can be seen from the fitting curve of Figure $11 \mathrm{~b}$ that the maximum hardness is between B $0.1 \mathrm{wt} . \%$ and B $0.2 \mathrm{wt} . \%$.
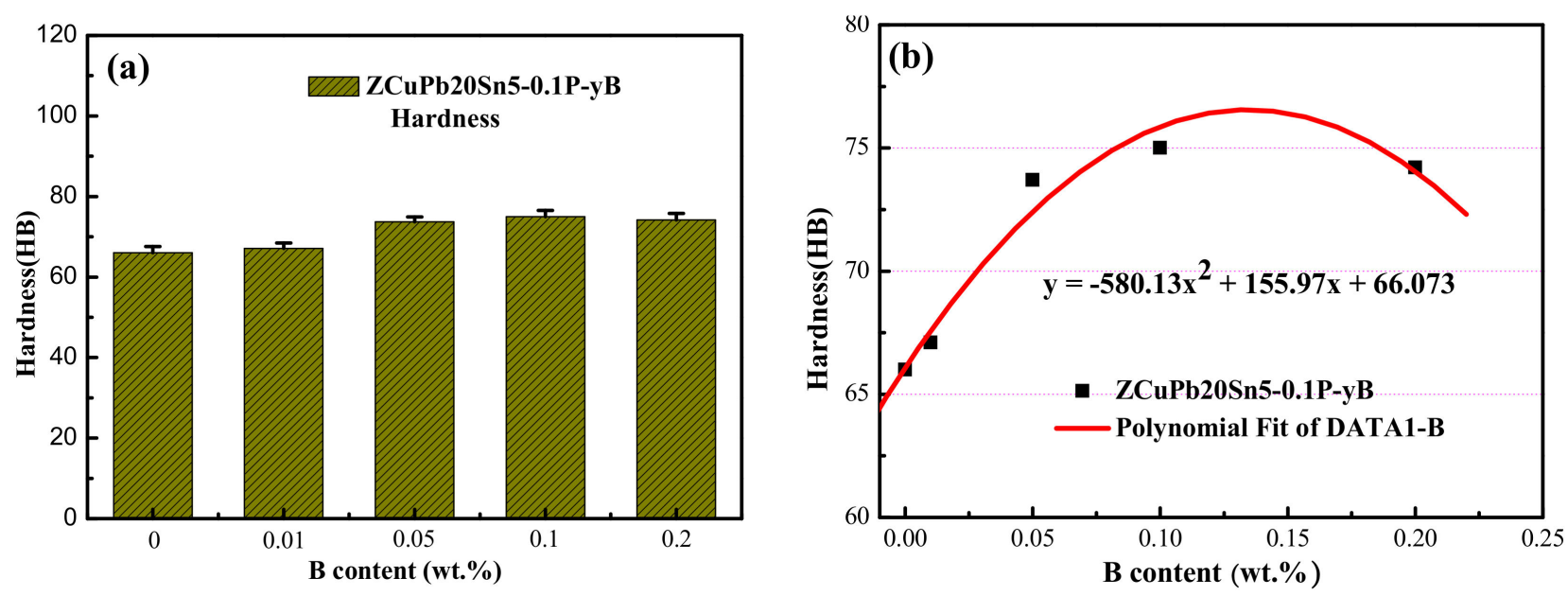

Figure 11. Hardness of $\mathrm{ZCuPb} 20 \mathrm{Sn} 5$ alloy with different element contents. (a) Hardness of ZCuPb20Sn5-0.1P-yB; (b) ZCuPb20Sn5 alloy hardness fitting curve.

The fitting curve is shown in Figure 11b. It can be seen that with the increase of $\mathrm{B}$ content, the hardness of $\mathrm{ZCuPb} 20 \mathrm{Sn} 5$ alloy shows a parabolic increase and decrease trend. The law of increase and decrease satisfies the Formula (1), and every point in the experimental data is basically on the curve.

$$
\mathrm{y}_{\mathrm{B}}=-580.13 \mathrm{x}_{\mathrm{B}}^{2}+155.97 \mathrm{x}_{\mathrm{B}}+66.073
$$

where, $y$ is the hardness of ZCuPb20Sn5 alloy, and the unit is HB. $x_{B}$ is the content of $\mathrm{B}$ added, and the unit is: wt.\%.

After analyzing the hardness of the above ZCuPb20Sn5-0.1P-yB alloy material, it can be found that the addition of $B$ can increase the hardness of the material, and the increase law satisfies the change law of the formula $\mathrm{y}_{\mathrm{B}}=-580.13 \times \mathrm{B} 2+155.97 \times \mathrm{B}+66.073$. With the increase in $\mathrm{B}$ content, the hardness shows a trend of increasing first and then decreasing, with little change. Consistent with the change rule of tensile strength, when the addition amount of $B$ is $0.1 \mathrm{wt} . \%$, it reaches the maximum value of $75.0 \mathrm{HB}$. Compared with the absence of $\mathrm{B}$, the hardness increased by $9 \mathrm{HB}$, an increase of $13.6 \%$. The main reason for the increase in hardness is that the addition of $\mathrm{B}$ can generate second phase particles. From the $\mathrm{ZCuPb} 20 \mathrm{Sn} 5$ alloy structure, it can be seen that the addition of $\mathrm{B}$ produces second phase particles, which leads to an increase in the hardness of the alloy material. But the content of this phase is very small, so the hardness change is not big, basically within the error range. 


\subsubsection{Analysis of Tensile Strength Data}

After sampling and measuring the cast ZCuPb20Sn5-yB alloy sample, the as-cast mechanical properties of different schemes at room temperature are obtained. According to the obtained mechanical property data, the columnar distribution diagram of the tensile strength of different elements is drawn, as shown in Table 3. According to the tensile strength of the alloy, Equation and curve in Figure 12b are fitted.

Table 3. $\mathrm{Ni}_{4} \mathrm{~B}_{3}$ elastic constant table.

\begin{tabular}{cccccccc}
\hline C11 & $\mathbf{C 1 2}$ & $\mathbf{C 1 3}$ & $\mathbf{C 1 4}$ & $\mathbf{C 1 5}$ & $\mathbf{C 1 6}$ & C22 & C23 \\
\hline 449.951 & 148.690 & 165.651 & -0.075 & -6.294 & 2.496 & 346.940 & 130.630 \\
$\mathrm{C} 24$ & $\mathrm{C} 25$ & $\mathrm{C} 26$ & $\mathrm{C} 33$ & $\mathrm{C} 34$ & $\mathrm{C} 35$ & $\mathrm{C} 36$ & $\mathrm{C} 44$ \\
0.925 & -49.817 & 0.292 & 342.235 & 1.309 & -12.782 & 0.111 & 78.135 \\
$\mathrm{C} 45$ & $\mathrm{C} 46$ & $\mathrm{C} 55$ & $\mathrm{C} 56$ & $\mathrm{C} 66$ & & & \\
0.015 & -15.545 & 83.919 & -1.342 & 107.640 & & & \\
\hline
\end{tabular}
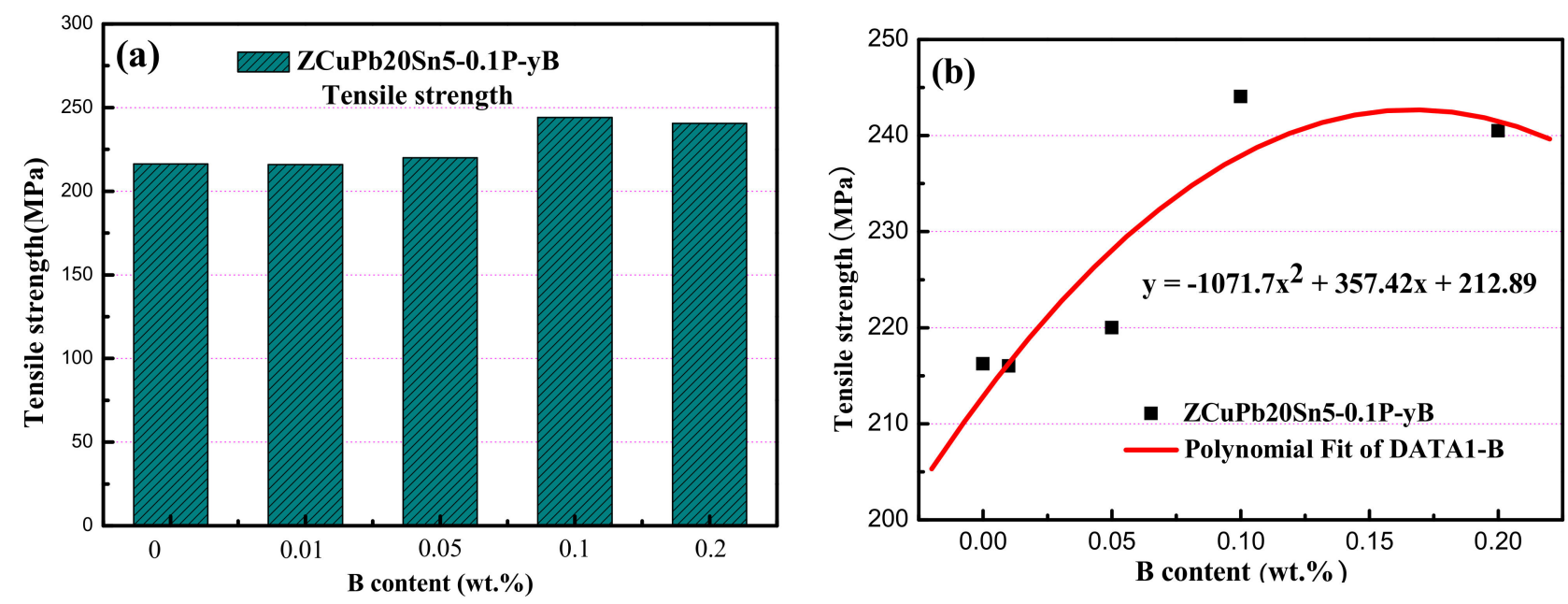

Figure 12. Tensile strength of $\mathrm{ZCuPb} 20 \mathrm{Sn} 5$ alloy with different element contents. (a) tensile strength ofZCuPb20Sn5-0.1P-yB; (b) Fitting curve.

Figure 12a shows the change trend graph of the tensile strength of ZCuPb20Sn5 alloy with different element content. It can be seen from the bar graph that the tensile strength of the $\mathrm{ZCuPb} 20 \mathrm{Sn} 5$ alloy increases with the increase in the amount of boron added. From no addition of $\mathrm{B}$ to $0.01 \mathrm{wt} . \%$, the tensile strength increased by $3 \mathrm{MPa}$, an increase of $1.42 \%$ from $0.01 \mathrm{wt} . \% \mathrm{~B}$ to $0.05 \mathrm{wt} . \% \mathrm{~B}$. In the process of increasing from $0.05 \mathrm{wt} . \% \mathrm{~B}$ to $0.1 \mathrm{wt} . \% \mathrm{~B}$, the tensile strength increased by $20 \mathrm{MPa}$, with an increase of $9.09 \%$; it can be seen that the phosphorus addition amount is less than or equal to $0.1 \mathrm{wt} . \% \mathrm{~B}$. With the increase in boron content, the tensile strength increases, and the increase is not large; the maximum increase of the tensile strength is $9.09 \%$. According to the fitting curve, it can be seen that the peak value is reached when the amount of B is $0.1 \mathrm{wt} . \%$, and the tensile strength is $244 \mathrm{MPa}$.

$$
\mathrm{y}_{\mathrm{B}}=-1071.7 \mathrm{x}_{\mathrm{B}}^{2}+357.42 \mathrm{x}_{\mathrm{B}}+212.89
$$

Among them, $y$ represents the content of $\mathrm{B}$, the unit is wt.\%; $\mathrm{y}_{\mathrm{B}}$ is the corresponding tensile strength, the unit is MPa.

The addition of boron can combine with some elements in the ZCuPb20Sn5 alloy to produce high-melting-point boride, which serves as the nucleation matrix of the crystal grains during the solidification process to promote the nucleation rate, refine the structure, and improve performance. When $\mathrm{B}$ is added to $\mathrm{ZCuPb} 20 \mathrm{Sn} 5$ alloy, the high melting point boride formed is mainly a nickel-boron phase. The addition of boron has an impact on 
$\mathrm{Pb}, \mathrm{S}, \mathrm{P}$, etc., from the original distribution in grain boundaries and dendrites to uniform distribution in the crystal. The boride can completely spheroidize $\mathrm{Cu}_{2} \mathrm{O}$ and $\mathrm{Cu}_{2} \mathrm{~S}$ or even disappear completely, and the inclusions can be precipitated from the solid solution state through the boride. In addition, in terms of lead segregation, high melting point borides can be distributed on the copper matrix, and $\alpha$-phase dendrites are precipitated and refined in advance, which inhibits the enrichment of lead, reduces the segregation of lead, and improves the mechanical properties.

\subsubsection{Analysis of Elongation Data}

Figure 13 is a histogram of the elongation distribution of ZCuPb20Sn5 alloy with different boron content; the elongation does not change significantly.

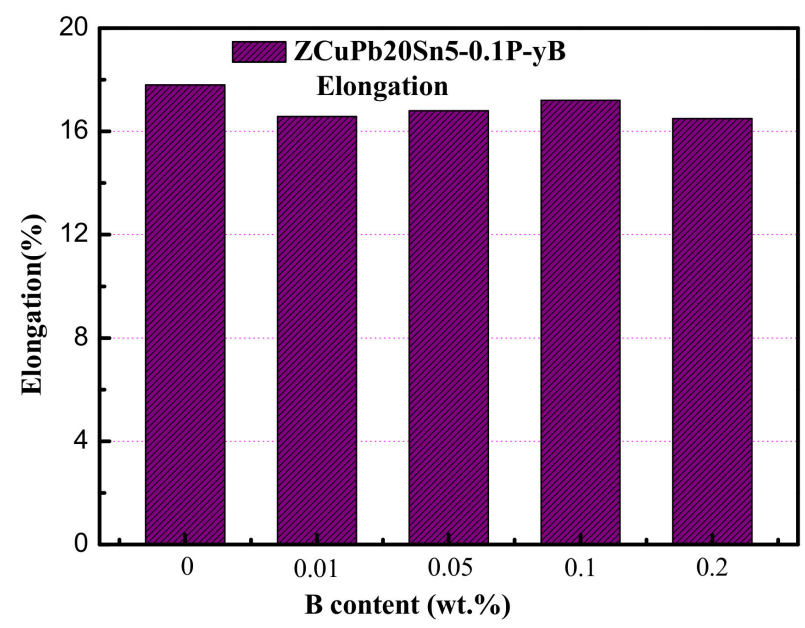

Figure 13. Elongation of $\mathrm{ZCuPb} 20 \mathrm{Sn} 5$ alloy with different $\mathrm{B}$ element contents.

It can be seen from the histogram 13 that the elongation of $\mathrm{ZCuPb} 20 \mathrm{Sn} 5$ alloy shows a trend of first increasing and then decreasing with the increase of boron, but the increase and decrease are relatively small. The elongation is basically maintained between $16 \%$ and $17 \%$, which is relatively stable. It shows that the addition of boron has little effect on the elongation of the alloy. However, the addition of boron can improve the mechanical properties, and an appropriate amount of boron can replace part of the role of phosphorus, and at the same time offset the hot embrittlement caused by high phosphorus.

The smaller the crystal grains, the more uniform the deformation-therefore, the smaller the stress concentration generated, which helps to improve the plasticity of the material. The addition of $\mathrm{B}$ can refine the structure of the $\mathrm{ZCuPb} 20 \mathrm{Sn} 5$ alloy, so the plasticity is improved. At the same time, the smaller and finer the crystal grains, the greater the number of crystal grains in a certain volume. Therefore, when the amount of deformation is the same, the deformation in the crystal grains is dispersed in more crystal grains, so that the deformation in each crystal grain becomes smaller and uniform, and the excessive stress concentration phenomenon is eliminated. Moreover, as the crystal grains become smaller, the grain boundaries become more and more tortuous, thereby preventing the cracks from continuing to propagate and making the cracks undergo greater plastic deformation before fracture. In this way, metal materials exhibit higher plasticity and toughness. However, because the second phase particles are generally hard, their size is too large, which easily causes brittle fracture of the material during the deformation process, thereby reducing its elongation.

\subsubsection{Fracture Morphology Analysis}

Figure 14 is the fracture scan photograph of ZCuPb20Sn5-yB alloy material. 

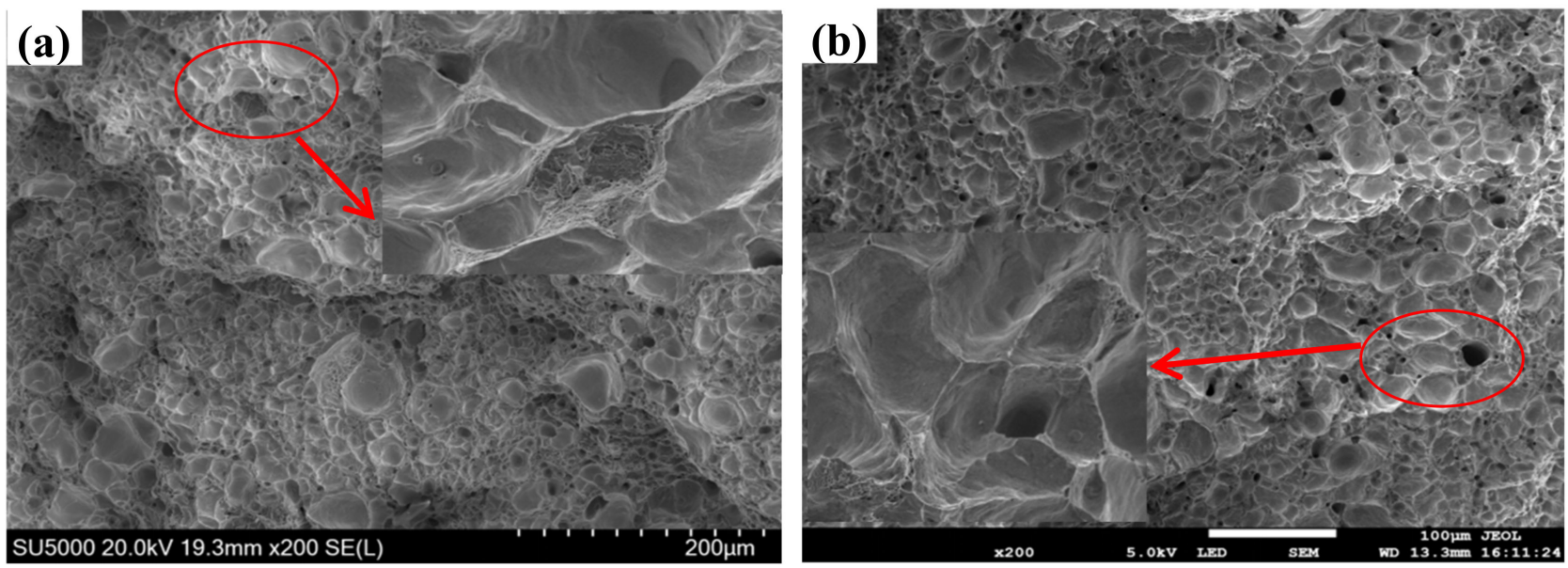

Figure 14. Tensile fractographs of ZCuPb20Sn5-yB alloy. (a) B 0.1; (b) B 0.2.

It can be seen from Figure 14 that after adding B, there are obvious dimples at the fracture. Therefore, the fracture mode of the two materials is plastic fracture. Moreover, the addition amount is different, the size and shape of the dimples are different. It is known from the previous results that the elongation of $\mathrm{ZCuPb} 20 \mathrm{Sn} 5$ alloy begins to decrease after adding boron over $0.05 \mathrm{wt} . \%$. It can be seen from Figure $14 \mathrm{ZCuPb} 20 \mathrm{Sn} 5-0.1 \mathrm{P}-\mathrm{yB}$ alloy fracture morphology that after adding B0.1 wt.\%, the size of the dimples in the tissue is not large, but the dimples are deep and relatively uniform. However, after adding $0.2 \mathrm{wt} . \% \mathrm{~B}$, it is obvious that black large particles exist at the fracture dimples in the alloy structure, indicating that the inclusions or the second phase are not only the holes formed around the inclusions or precipitates when the material undergoes plastic deformation. The resulting microporous fracture, and with the growth of the second phase and inclusions, prevents dislocation slippage and creates holes, which leads to slippage separation fractures of the material. Therefore, when the B content is increased to $0.2 \mathrm{wt} . \%$, the elongation decreases slightly.

Due to the addition of element $\mathrm{B}$, the grain size of the $\mathrm{ZCuPb} 20 \mathrm{Sn} 5$ alloy structure becomes smaller and the stress concentration is weakened, thereby improving the tensile strength of the alloy. At the same time, after the addition of B, the second phase hard particles generated are dispersed in the matrix grains, on the grain boundaries or aggregated into agglomerates, which hinder the dislocation during the solidification process and achieve the strengthening effect. Therefore, the strength of the $\mathrm{ZCuPb} 20 \mathrm{Sn} 5$ alloy material is improved.

\subsubsection{Strengthening Analysis of the Second Phase $\mathrm{Ni}_{4} \mathrm{~B}_{3}$ Particles}

In the first principles, the CASTEP and Forcite Plus modules are used to simulate the second phase $\mathrm{Ni}_{4} \mathrm{~B}_{3}$ appearing in the alloy ZCuPb20Sn5-yB, and the elastic constants of the particles in this phase are obtained in Table 4 , and according to the relevant formula calculate the bulk modulus (B), shear modulus (G), Young's modulus (E), and Poisson's ratio $(\mu)$ of the $\mathrm{Ni}_{4} \mathrm{~B}_{3}$ phase, as shown in Table 3 .

Table 4. $\mathrm{Ni}_{4} \mathrm{~B}_{3}$ related modulus data sheet Unit: GPa.

\begin{tabular}{ccccccccc}
\hline & $\mathbf{B}_{\mathbf{V}}$ & $\mathbf{B}_{\mathbf{R}}$ & $\mathbf{B}_{\mathbf{H}}$ & $\mathbf{G}_{\mathbf{V}}$ & $\mathbf{G}_{\mathbf{R}}$ & $\mathbf{G}_{\mathbf{H}}$ & $\mathbf{E}$ & $\boldsymbol{\sigma}$ \\
\hline $\mathrm{Ni}_{3} \mathrm{P}$ & 204.35 & 204.31 & 204.33 & 63.22 & 60.90 & 62.06 & 169.07 & 0.36 \\
$\mathrm{Cu}_{3} \mathrm{P}$ & 114.43 & 113.31 & 113.87 & 45.51 & 44.27 & 44.89 & 119.03 & 0.33 \\
$\mathrm{Ni}_{4} \mathrm{~B}_{3}$ & 225.45 & 211.68 & 218.57 & 100.22 & 92.42 & 96.32 & 251.95 & 0.31 \\
\hline
\end{tabular}

Remarks: Bulk modulus (B), shear modulus (G), Young's modulus (E), Poisson's ratio ( $\sigma$ ). 
From the data in Table 4, it can also be seen that the Young's modulus and shear modulus of $\mathrm{Ni}_{4} \mathrm{~B}_{3}$ are much greater than those of $\mathrm{Ni}_{3} \mathrm{P}$. The $\mathrm{Ni}_{4} \mathrm{~B}_{3}$ phase $\mathrm{C} 44$ is also larger than the $\mathrm{Ni}_{3} \mathrm{P}$ phase. Therefore, it can be judged that the $\mathrm{Ni}_{4} \mathrm{~B}_{3}$ phase particles are hard particles with a hardness greater than that of $\mathrm{Cu}_{3} \mathrm{P}$.

By calculating the $\mathrm{G} / \mathrm{B}$ (Pugh ratio) value of $\mathrm{Ni}_{4} \mathrm{~B}_{3}$ phase:

Pugh ratio of $\mathrm{Ni}_{4} \mathrm{~B}_{3}: \mathrm{G}_{\mathrm{V}} / \mathrm{B}_{\mathrm{V}}=100.22 / 225.45=0.445$

$\mathrm{G}_{\mathrm{R}} / \mathrm{B}_{\mathrm{R}}=92.42 / 211.68=0.437$

$\mathrm{G}_{\mathrm{H}} / \mathrm{B}_{\mathrm{H}}=96.32 / 218.57=0.441$

The calculation results show that the $G / B$ of the $\mathrm{Ni}_{4} B_{3}$ phase is less than 0.5 , but close to 0.5 , indicating that this phase material is a ductile phase, but ductility is not high.

\section{Conclusions}

By adding different alloying elements to study the structure and properties of ZCuPb20Sn5 alloy, the following conclusions are drawn:

(1) The addition of B has an obvious refinement effect on the structure of ZCuPb20Sn5 alloy, which can refine the $(\mathrm{Cu})$ equiaxed crystal and reduce the lead particles. When $\mathrm{B}$ is not added, the average diameter of the lead particles is $30.0 \mu \mathrm{m}$, and $0.1 \mathrm{wt} . \% \mathrm{~B}$ is added. It is $24.8 \mu \mathrm{m}$, which is $17.3 \%$ thinner. The reason for the grain refinement is that when the $\mathrm{ZCuPb} 20 \mathrm{Sn} 5$ alloy is solidified, boron is easily enriched at the grain boundary, which affects the diffusion of solute atoms at the solidification interface, inhibits the growth of grains, refines the grains, prevents the sinking of lead, and distributes it evenly between the dendrites. When the amount of $\mathrm{B}$ added is $0.1 \mathrm{wt} . \%, \mathrm{Ni}_{4} \mathrm{~B}_{3}$ phase is formed in the alloy.

(2) The tensile strength of $\mathrm{ZCuPb} 20 \mathrm{Sn} 5$ alloy material increases first and then decreases with the increase of $B$ content. The formula $y_{B}=-1071.7 x_{B}+357.42 x_{B}+212.89$ can be used to describe the change law. The increase in material hardness and elongation is not obvious. When the content of B is $0.1 \mathrm{wt} . \%$, the tensile strength reaches the maximum. Compared with the absence of $\mathrm{B}$, the tensile strength increased by $28 \mathrm{MPa}$, an increase of $13 \%$; the maximum hardness was $75.0 \mathrm{HB}$, an increase of $9 \mathrm{HB}$, the increase was $13.6 \%$, and the elongation was the maximum $17.2 \%$.

(3) The main reason for the increase in the strength of the $\mathrm{ZCuPb20Sn} 5$ alloy is that the addition of $\mathrm{B}$ can generate high melting point $\mathrm{Ni}_{4} \mathrm{~B}_{3}$ particles, resulting in dispersion strengthening. At the same time, the addition of $B$ can refine the grains, produce fine-grain strengthening, and increase the strength of the alloy. As the B content continues to increase, the resulting high-melting-point second phase changes from granular to lumpy, or even large-scale lumps, which reduces the fluidity of the alloy liquid and causes defects such as shrinkage and porosity in the structure, resulting in a decrease in mechanical properties.

Author Contributions: Conceptualization, Z.W. and Z.Y.; methodology, Y.L.; software, F.S.; validation, X.R., Y.K., W.L. and M.W.; formal analysis, X.R.; investigation, X.R.; resources, H.X.; data curation, G.Z.; writing—original draft preparation, X.R.; writing—review and editing, X.R.; visualization, G.Z.; supervision, G.Z.; project administration, X.R.; funding acquisition, X.R. All authors have read and agreed to the published version of the manuscript.

Funding: The study was conducted according to the guidelines of the Declaration of Helsinki, and approved by the Institutional Review Board (or Ethics Committee) of Department of Mechanical Engineering, Taiyuan Institute of Technology, Taiyuan 030008, China and the Opening Project of Shanxi Key Laboratory of Controlled Metal Solidification and Precision Manufacturing, North University of China (MSPM202004).

Institutional Review Board Statement: Not applicable.

Informed Consent Statement: Not applicable.

Data Availability Statement: The data presented in this study are available upon request from the corresponding author.

Conflicts of Interest: The authors declare no conflict of interest. 


\section{References}

1. Liao, L.; Li, C. Development and Application of RE-Cu Additives. Spec. Cast. Nonferrous Alloy. 1995, $20-21$.

2. Wang, J.; Jiang, X. The effect of boron on the structure and corrosion properties of HAl77-2 aluminum brass. Chin. J. Mater. Res. 1996, 10, 597-602.

3. Fasoyinu, F.A.; Sadayappan, M.; Cousineau, D.; Zavadil, R.; Sahoo, M. Effects of Grain Refinement on Hot Tear Resistance and Shrinkage Characteristics of Permanent Mold Cast Yellow Brass(C85800). AFS Trans. 1998, 107, 327-337. [CrossRef] [PubMed]

4. Wang, J.; Jiang, X.; Li, S. The effect of boron on the structure and properties of copper alloys. Chin. J. Mater. Res. 1997, 11, 381-386.

5. Wang, J.; Jiang, X. Microstructure and mechanical properties of boron-added HAl77-2 aluminum brass. Acta Met. Sin. 1995, 31A, 315-319.

6. Wang, J.; Jiang, X. The effect of trace boron on the structure and properties of 70Cu-30Ni alloy. Acta Metall. Sin. 1995, 31A, 266-271.

7. Ni, Z.; Cheng, J.; Liu, Z. The effect of B modification on the refinement of HPb59-1 brass. Spec. Cast. Nonferrous Alloy. 2007, 27, 70-72.

8. Zhang, A.; Yan, M.; Zeng, Q. The refinement and modification of rare earth boron and zirconium in HPb59-1 brass effect. Casting 2005, 540, 1017-1021.

9. Zou, J.; Zhao, J.; Wang, X.; Liang, S. The effect of adding trace boron on the structure and properties of CuNiMnFe alloy. Chin. J. Nonferrous Met. 2013, 4, 1005-1011.

10. Li, Z.; Xiao, Z.; Jiang, Y.; Lei, Q.; Xie, J. Composition design, phase transformation and preparation of high-strength conductive copper alloys. Chin. J. Nonferrous Met. 2019, 29, 2009-2049.

11. Segall, M.D.; Lindan, P.J.D.; Probert, M.J.; Pickard, C.J.; Hasnip, P.J.; Clark, S.J.; Payne, M.C. First-principles simulation: Ideas, illustrations and the CASTEP code. J. Phys. Condens. Matter 2002, 14, 2717. [CrossRef]

12. Yang, X.; Hou, H.; Zhao, Y.; Yang, L.; Han, P. Mg17 Al12, Al2Y and Al2Ca phase stability and elastic properties first-principles study. Rare Met. Mater. Eng. 2014, 4, 875-880.

13. Fischer, T.H.; Almlof, J. General methods for geometry and wave function optimization. J. Phys. Chem. 1992, 96, 9768. [CrossRef] 